\title{
Standard Health Level Seven for Odontological Digital Imaging
}

\author{
Mauricio Abril-Gonzalez, DDM, MBA, \\ Fernando A. Portilla, Eng, MIT, \\ and Marta C. Jaramillo-Mejia, MD, $\mathrm{MPH}^{3}$ \\ ${ }^{1}$ Coomeva, Cali, Colombia. \\ ${ }^{2}$ Health Informatics Standards Specialist, National Electronic \\ Health Record Program, Salud.uy AGESIC, Uruguay. \\ ${ }^{3}$ Organizational Management Department, ICESI University, \\ Cali, Colombia.
}

\begin{abstract}
Background: A guide for the implementation of dental digital imaging reports was developed and validated through the International Standard of Health Informatics-Health Level Seven (HL7), achieving interoperability with an electronic system that keeps dental records. Introduction: Digital imaging benefits patients, who can view previous close-ups of dental examinations; providers, because of greater efficiency in managing information; and insurers, because of improved accessibility, patient monitoring, and more efficient cost management. Finally, imaging is beneficial for the dentist who can be more agile in the diagnosis and treatment of patients using this tool. Materials and Methods: The guide was developed under the parameters of an HL7 standard. It was necessary to create a group of dentists and three experts in information and communication technologies from different institutions. Discussion: Diagnostic images scanned with conventional radiology or from a radiovisiograph can be converted to Digital Imaging and Communications in Medicine (DICOM) format, while also retaining patient information. The guide shows how the information of the health record of the patient and the information of the dental image could be standardized in a Clinical Dental Record document using international informatics standard like HL7-V3-CDA document (dental document Level 2). Since it is an informatics standardized document, it could be sent, stored, or displayed using different devices-personal computers or mobile devices-independent of the platform used. Conclusions: Interoperability
\end{abstract}

using dental images and dental record systems reduces adverse events, increases security for the patient, and makes more efficient use of resources. This article makes a contribution to the field of telemedicine in dental informatics. In addition to that, the results could be a reference for projects of electronic medical records when the dental documents are part of them.

Keywords: teledentistry, teleradiology, telehealth, e-health

\section{Introduction}

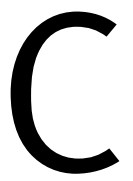

olombia's Healthcare System (CHCS) is compulsory for the entire population. It contains healthcare plans (the EPS-Empresas Promotoras de Salud), which are responsible for offering, at a minimum, the compulsory health plan (POS-Plan Obligatorio de Salud) by private or Public Healthcare Providers (IPS-Instituciones Prestadoras de Servicios de Salud). ${ }^{1,2}$

CHCS began in 1993 by "Law Number 100" (Ley 100 de 1993), the insurance affiliation is mandatory. ${ }^{1}$ The CHCS has principally two regimes: (1) Contributory Regime with $40 \%$ of the Colombian population and (2) Subsidized Regime, covering 53\% of the population; the latter for the poorest population. ${ }^{3,4}$ For both regimes, the CHCS includes one package of benefits, stipulated by the POS. ${ }^{5}$

The population has a basic plan for oral health, it includes preventive oral health, general dentistry (with caries treatment), and even some of the specialist services, like endodontic (includes "prevention, diagnosis, and treatment of diseases of the dental pulp and their sequelae"6) and maxillofacial surgery (does not include aesthetics). ${ }^{5}$

In Colombia, it is not mandatory to use unified digital medical and dental records, although some private or public providers use it. In dental services it is not common to use digital dental diagnostic images integrated with dental records. Although there are some IPS in Colombia with electronic dental record systems and technology to digitize dental

(C) Mauricio Abril-Gonzalez, et al. 2017; Published by Mary Ann Liebert, Inc. This Open Access article is distributed under the terms of the Creative Commons Attribution Noncommercial License (http://creativecommons.org/licenses/by-nc/4.0/) which permits any noncommercial use, distribution, and reproduction in any medium, provided the original author(s) and the source are credited. 
$\mathrm{X}$-rays, both electronic records are not integrated, and these two systems do not work together.

On the other hand, dental X-rays are the main diagnostic tool used by dental professionals; however, the IPS stores images by convenience, resulting in problems identifying corresponding radiographs for each patient and in presenting images deteriorated or lost. This situation can generate the need for a new appointment to "make another X-Ray," which means exposing the patient to more radiation and increasing operating costs and inefficiency.

This affects decisions and processes like diagnosis, treatment, audit, medical records, and patient monitoring, which in turn generate a general inefficiency in the use of IPS resources and affect the quality of provided health services to the patient. On top of this, organizations that produce digital dental radiography in Colombia are only able to share the X-rays by email, because the electronic records are not integrated.

Dental Informatics evolves alongside the developments and innovations in medical informatics. Many specifications that are part of different standards are not available for dental application and use. ${ }^{7,8}$ For example, in vocabulary systems such as the International Classification of Diseases (ICD)-10, representation of dental diagnostics is minimal. ICD-10 uses four characters to classify the diseases, the first three characters define the diseases category and the fourth defines subcategories. The ICD-DA (Application of the International Classification of Diseases to Dentistry and Stomatology) is a derivation from the ICD-10 used to generate dental diagnoses, they add a fifth character for more detail, however, it is not widely known in general.

The structure supports a health services network consisting of IPS. In 2011, a healthcare reform created a new stage in the information system, including the establishment of mandatory electronic medical records beginning in 2013, without defining general standards and excluding specifications for the exchange of information about dental diagnostic images. ${ }^{9}$

In Colombia, there is room for technological development and some experiments have been described regarding the digitization of dental records. For example, CES University in Medellin (private) and Cauca University in Popayán (public) developed a guide for the implementation of the Health Level Seven (HL7) for the Clinical Document Architecture (CDA) standard. ${ }^{10}$

There has been movement toward the administration of electronic dental records as mentioned in the National Development Plan 2010-2012, which is supported by the National University of Colombia, but none of them has worked to integrate standard diagnostic images with patients' medical records. ${ }^{11}$
Since 2007, Colombia has been working on the study and analysis of the methodology for the implementation of international standards. HL7 and diverse committees are studying the different components to implement the standards in the country, but there is not an HL7 committee for dental issues because the standard does not exist. ${ }^{2}$

This study proposes the standardization of radiological images for dental patients to unify the periapical (refers to the area around the apex of the tooth ${ }^{6}$ ) and panoramic radiology (it is a method for obtaining images by the synchronous rotation of the X-ray source and image receptor around the stationary patient ${ }^{12}$ ) reports with conventional radiological images, or radiovisiography (refers to a rapid imaging system capable of producing clinically acceptable periapical images ${ }^{13}$ ), which can be sent or used by another dental information system when interoperability or integration of information is required.

The article presents, first, a conceptual framework about the tools to use, the methodology, the results of the implementation guide, and the discussion and benefits of the developed standard.

\section{Conceptual Framework}

In recent years, ICT (information and communication technologies) in health and dentistry have reached an important development that has allowed the penetration of the different contexts of the sector organizations. ${ }^{14}$

\section{DENTAL RADIOGRAPHIC SYSTEMS}

The oldest of the methods still used is the conventional system with radiographic film. The first digital systems appeared in the 1980s with the digitization of conventional images obtained from radiographic films. The first intraoral digital systems were described in $1988 .{ }^{15}$ Consequently, there are two methods:

1. Indirect: Digitized radiography, either scanned, photographed, or filmed by digital video camera, useful for keeping records of tests performed and cases of interest.

2. Direct: Captures the image of the oral structures through sensors that transmit directly to the computer. It is possible to get better image quality and provide a benefit to the patient, because it reduces exposure to radiation. ${ }^{16}$

\section{INTEROPERABILITY AND STANDARDS IN HEALTH}

This allows an exchange of data between information systems with different technology platforms. It is conceptualized as three interdependent types. ${ }^{17,18}$ 
1. Technical interoperability: Sends data from system A to system $B$ and is able to reduce the problem of location and distance. The meaning of what is being exchanged is immaterial.

2. Semantic interoperability: Ensures that both system $A$ and system B understand the information being exchanged. This allows systems to understand, interpret, and use information without ambiguity. It is specific to domains and contexts, involves the use of encoders and identifiers or controlled vocabularies. It is at the heart of what is usually known as interoperability in health.

3. Interoperability of process: 0ccurs when processes are coordinated, enabling organizations to process systems $A$ and $B$ together.

\section{HL7 STANDARD}

There are different computer applications in health contexts because of the biotechnology industry and ICT, which have been developing connectivity standards for health applications since the 1980s. The HL7 standard has been one of the most accepted and it is oriented toward sharing messages and documents. The Standards Developing Organization (SD0), made up of 31 associated countries, recognizes it and is developing the most widely used standards in health interoperability. The SDO does not develop software, but it provides diverse specifications for health organizations, so they can have interoperable systems. That is why most of the industry uses and supports the development of HL7 in the six continents. ${ }^{19}$

\section{CLINICAL DOCUMENT ARCHITECTURE}

Is an international standard that allows the definition of clinical electronic documents using XML, its content could support different types of information, like tests or images with different semantic levels. The CDA Release 2 $(\mathrm{CDA} / \mathrm{r} 2)$ is a standard widely used in the definition of the documents that are exchanged in an interoperability context. ${ }^{20,21}$

\section{DIGITAL IMAGING AND COMMUNICATIONS IN MEDICINE (DICOM)}

This unifies the format and exchange of information between different imaging equipment and information systems for image processing. DICOM acts as a universal standard between this equipment and the file system, reducing the cost of buying additional storage infrastructure. ${ }^{22-24}$

\section{Materials and Methods}

The study follows the requirements in the management methodology described by Larman, which establishes a period to clarify the project agreements between parties, a stage known as "Statement of Work." ${ }^{25}$ Thus, meeting with dentists (general and specialists) and the managers of institutions to clarify the problems incurred because of lack of integration of dental clinical information systems and standardization of radiological images.

For the preparation of the proposed guide, it was necessary to create a group of dentists and experts in ICT from three types of institutions included:

1. EPS: A manager of the oral department and an audit specialist,

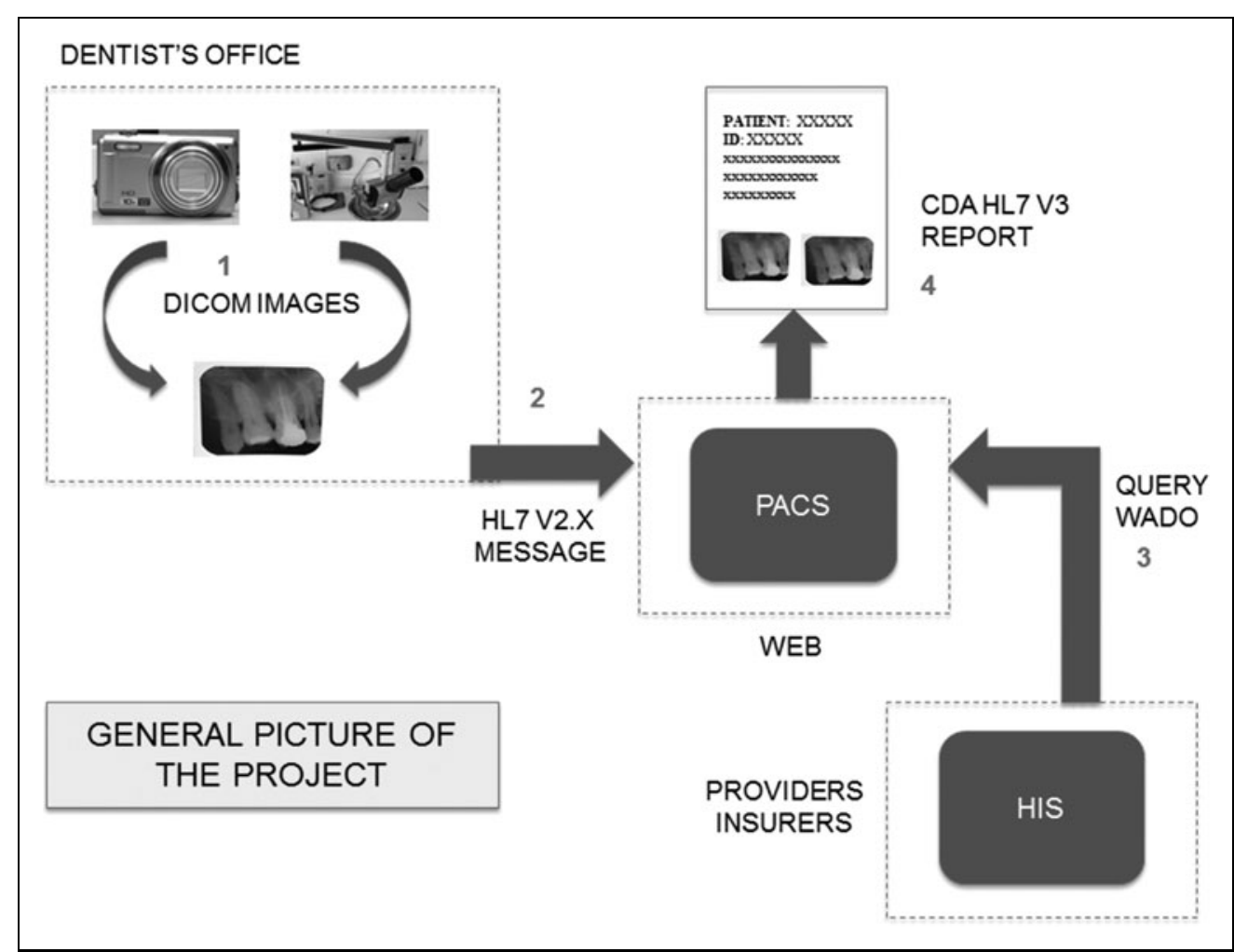

Fig. 1. General scheme of the project. 
2. IPS: A manager endodontic specialist, a dentistry management-health administration specialist, and an IPS informatics engineer.

3. An expert in informatics architect-systems engineer.

The guide was developed under the parameters of an HL7 standard, with the following stages: (1) defining the scope and necessity, (2) approach to the problem, with visits to dental IPS (at different levels of technology and specialty), (3) revision of the documentation using case histories, (4) definition of dental records to display, (5) preparing a document with data from periapical and panoramic reports, (6) proposing the architecture, (7) preparation and presentation of a demo from the implementation guide. Figure 1 illustrates the general scheme of the project.

The HL7 V3 CDA/r2 Clinical standard was used to develop the guide. A demo model will be tested; which can be validated subsequently in Colombia by the technical committee.

\section{Results}

Once the guide proposed in the methodology is developed, it is possible to map the information displayed in each field by obtaining four CDA documents (adapted from International HL7):

1. Mapping header CDA dentist$r y$, which contains data from the dental report, with 12 variables and the explanation of the data from the patient and the person that did the report.

2. Mapping body CDA periapical, which contains a periapical image, using DICOM or JPG format, with the description (four variables) and diagnosis, according to the ICD CIE 10 (code and description).

3. Mapping body CDA panoramic, which also contains the image, using DICOM or JPG format, with the description in nine variables, including the airways and maxillary sinuses, temporomandibular joint, skeletal structures, and dentition.

\section{RESULT OF INTEROPERABILITY}

The search for digital images is performed by general dentists of IPS or specialists in dentistry, who are involved in the following activities: (1) signing on to the medical records system using an individual key access, (2) digitizing the user identification in the search module, (3) selecting dental records and downloading all user information. At this point, the dental professional can directly view digitized diagnostics, indicate the required one from the odontogram or from the evolution sheet. From the image, it is possible to display the date of the procedure, the dental treatment, the procedures that would be performed, the stage of the dental piece, the dentist that attended the patient, and the treatment received.

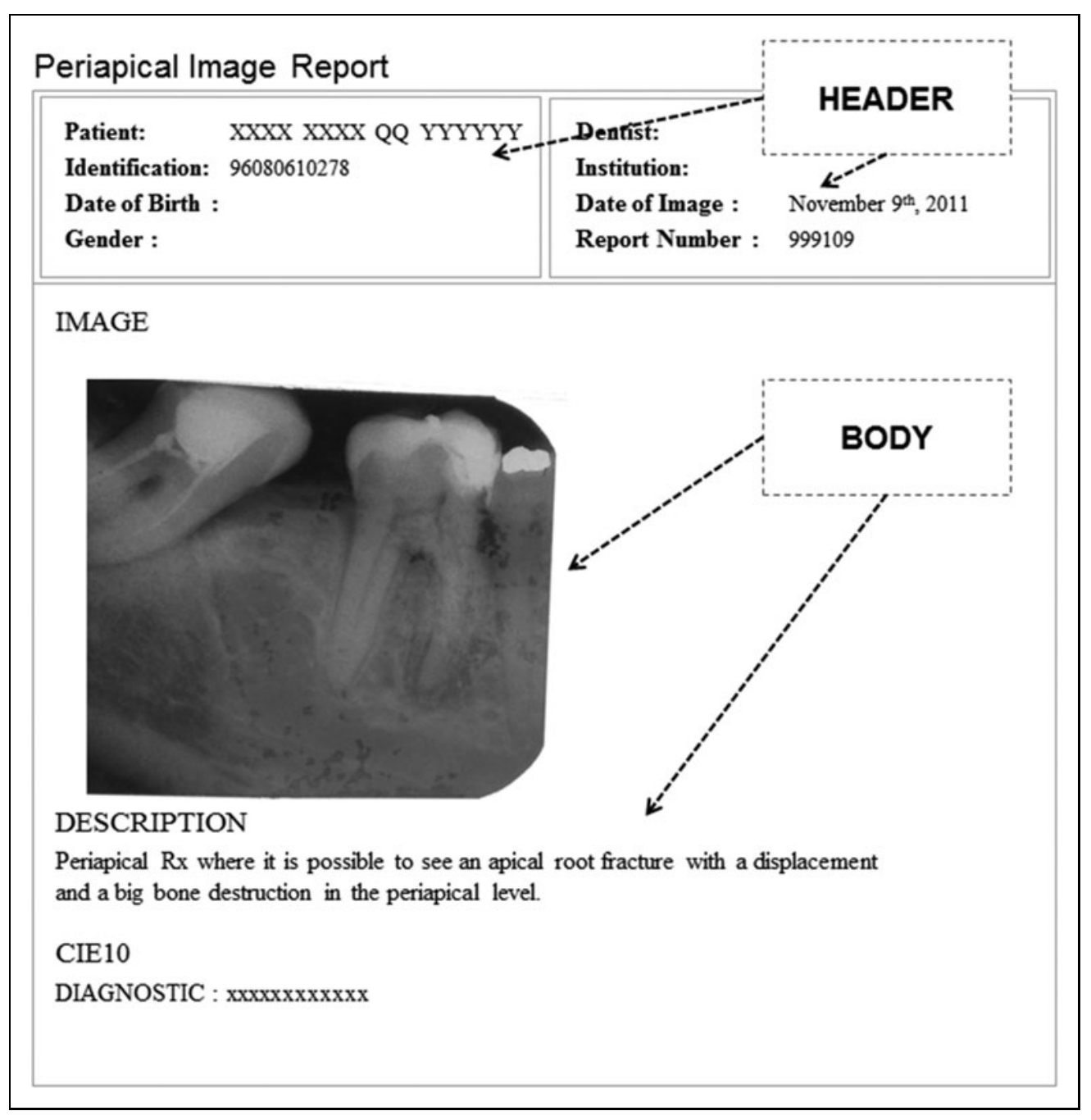

Fig. 2. Deployment of the dental periapical CDA. CDA, Clinical Document Architecture. 
This work specified the documents for the interoperability. The research was focused on the standardization of the imaging diagnostic documents for dentistry. The process to interchange the documents is out of the scope of this work. However, these CDA dentistry documents could be used in an interoperable model for interchange documents; one of the most known and used by the industry is the IHE XDS.b profile (in: www.ihe.net); this model is one of the most used by the National HER like Australia NEHTA, France Dossier, and Australia ELGA.

To maintain confidentiality, dental records can be accessed through a general dentist, specialist dentist, dentist auditor, patient, doctor (through electronic medical records), and repository studies contained in DICOM, where it is possible to find the informed consent and the images. At times, because
Colombia does not have a universal database with clinical records, the patient receives the radiograph, which could be deteriorated or lost.

The guide specifies three levels of compliance requirements:

- Level 1: Specifies the restrictions about the CDA head and the content of the document.

- Level 2: Specifies the restrictions about the "structured body" of the "clinical document" (CDA).

- Level 3: Describes a limited set of structured inputs, for referencing purposes and for accessing images within the report.

Two types of HL7 V3 CDA r2 documents were displayed based on the information specified in the Implementation Guide (Figs. 2 and 3).

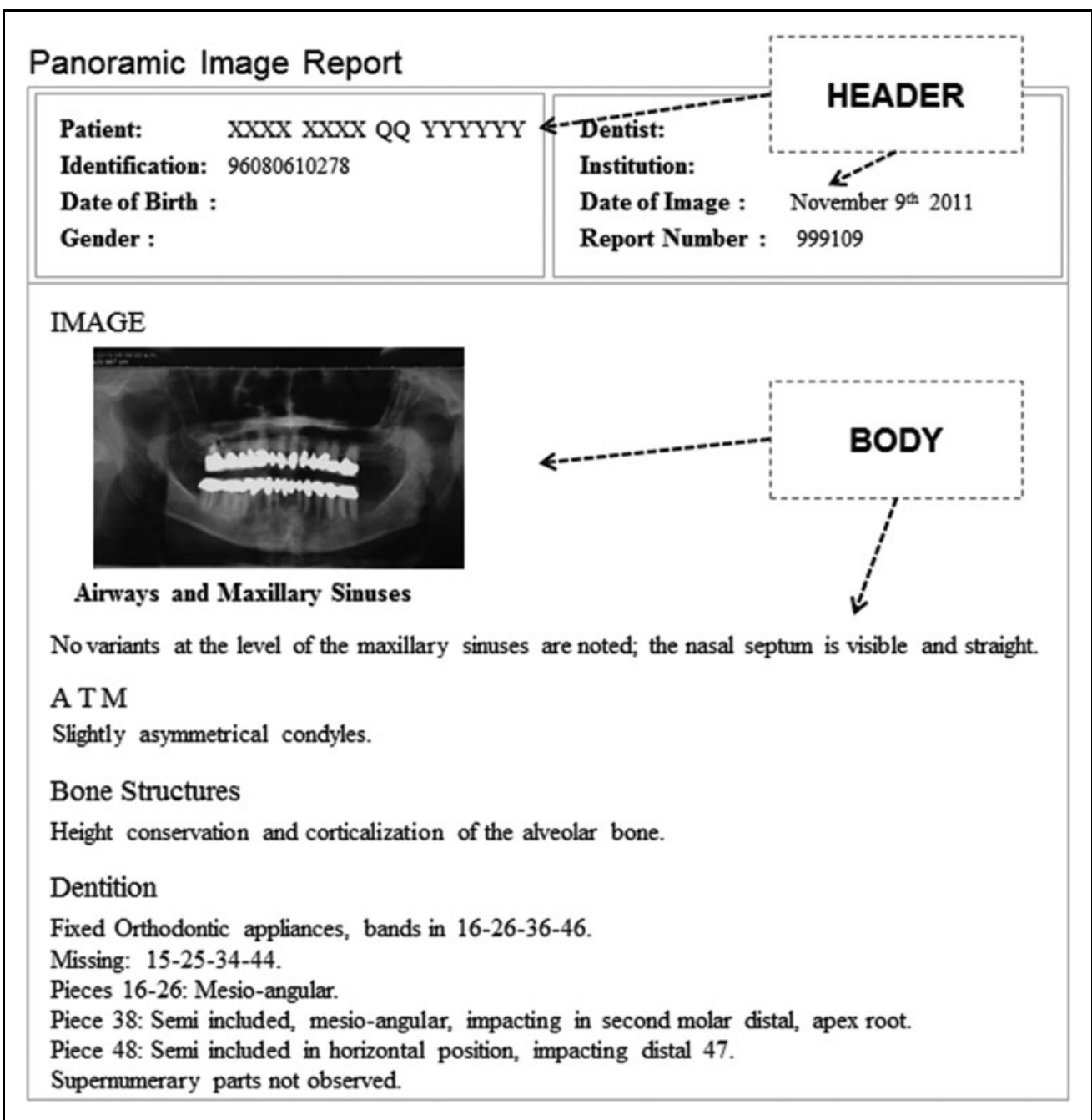

Fig. 3. Deployment of the dental panoramic CDA.

\section{VALIDATION OF THE IMPLEMENTATION GUIDE}

We visited two IPS ascribed to the dental IPS network. These were chosen because they both use the electronic dental record system provided by the insurer. The two IPS, however, use different processes for scanning images; one, digitized pictures from digital photography with conventional radiography, whereas the other uses a radiovisiograph.

A demo about the Web site www .openhealth.com.co was performed with the front end of application of electronic medical records. From there, the screenshots of clinical history and evolution odontogram were linked. The demo links the clinical history screenshots and places the access to documents and radiology reports within the odontogram, as specified in the design flow graph (Fig. 4).

\section{OBSERVATIONS TO THE DEMO}

Once the demo was implemented, the dental professional made the following observations: 


\section{GONZALEZ ET AL.}

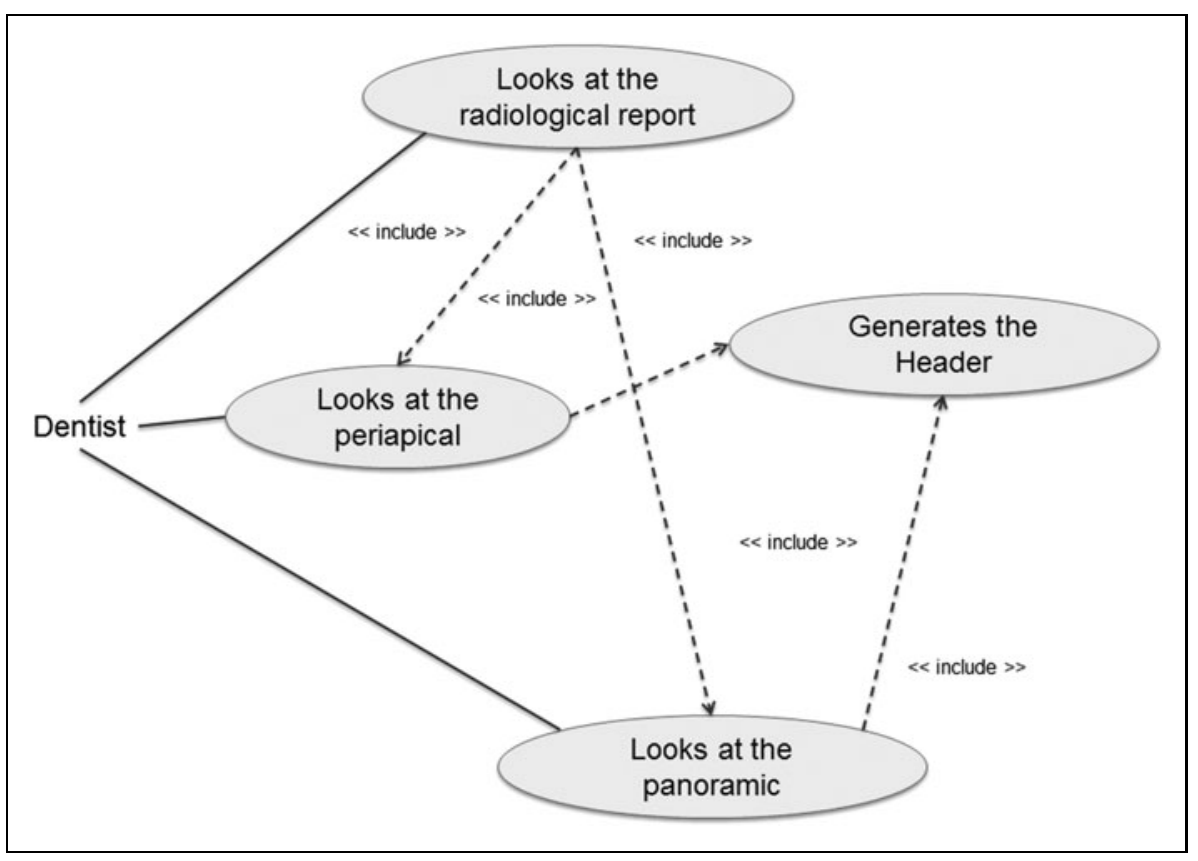

Fig. 4. Cases of use.

Related to the standardization of the radiology report format

- It is a necessity; it is important because of the dental images that contain the description or radiologic read.

- It is a friendly format; it allows interpretation and it has plenty of size.

- It is a complement to the actual technology (dental records, digital dental images, radiovisiographs, etc.) that has disintegrated.

- It could also be used with other reports, which are necessary to exchange in the dental sector.

Related to the benefits of the application

- The clinical history is not indexed to the patient's radiographic images and read.

- It improves the access to information.

- It allows access to information and images, no matter where the patient is.

- It provides safety for the patient.

- It is social and environmentally responsible.

- It has correct storage.

- It requires the dental professional to interpret the images.

Related to the suggestions

- The radiographic report should include observations of mandatory type, like a header with information about the patient, the diagnosis, and type of X-ray.
- It should differentiate the content of the observations from whoever performs the test and who requested it.

- There must be access from the evolution or the odontogram.

- There must be a mandatory requirement for medical record systems, which must be stored in sequential episodes, according to the patient's experience.

\section{OBSERVATIONS ON THE ARCHITECTURE}

The expert in health informatics platforms made the following comments on the proposed use of XDS (Extended Data Services) for sharing dental CDA:

- The architecture of a CDA document allows representation of different types of reports that conform to an electronic medical record.

- CDA documents can solve the need for interoperability of clinical documents, based on the knowledge of the IHE (Integrating the Healthcare Enterprise) and XDS.

\section{Discussion}

The development of the project showed that HL7 V3 CDA standard could be used to integrate Electronic Dental Record Information and dental radiological imaging. The clinical document includes information from different sources into a final dental document record. This CDA document generates significant applicability and utility for dental or no-dental organizations; when it is used in an interoperability context, it could support dentistry to improve the decision in the treatment of the patient. It could be even integrated to the Electronic Health Record of the patient.

Initially, we were concerned that the shape of the image acquisition would greatly affect the project, but during the validation phase, the visit and live interaction with dentists showed that it was not a constraint. The solution is independent from the type of X-ray scanning; images that are displayed in the CDA can come from a radiovisiograph $(30 \%$ of dental clinics that belong to the EPS) or manual digitization of radiographs.

As was seen in the discussions of the articles of the Conference on the Electronic Health Record (EHR) 2008, it is 


\section{STANDARD HL7 FOR ODONTOLOGICAL DIGITAL IMAGING}

necessary to unify the concept of including dental information in a person's comprehensive health history. ${ }^{i}$

In general, in Colombia, the dental report was not integrated with the medical record information. In the last few years, the efforts to integrate this information with the HER of each person have increased, and this stream has been supported by the EPS. The government still has not a National EHR.

Because other research groups such as the University EIA and the Cauca University developed the Dental Electronic Health Record (HCEO) based on CDA, it is important to harmonize these, unifying metadata, vocabulary, and concepts. ${ }^{10}$

The results allow data to be deployed to different units of dental services, improving accessibility and continuity, and reducing the costs to the patient, such as, travelling or complications in the treatment process (adverse events and patient safety). In the same way, interoperability with HCE can improve auditing and patient monitoring.

Since the Implementation Guide only presents the areas that are used in the dental document, the problem was simplified; it facilitated the understanding and feasibility of the pilot test. It is a process that requires preparation and knowledge, but using CDA, formalizes specifications and gives flexibility to its restrictions in other contexts. This can help other stakeholders develop new specifications for other areas.

The Implementation Guide can specify the models required for the analysis phase to support the specification standards of interoperability scenarios, as different guidelines were observed and all resolved differently this section.

In conclusion, this study not only provides a validated radiological image in dental reports that are more frequent, but it also supports the technological development of dental informatics, which is commonly found outside developments and standards that are usually done within the framework of medical informatics specifications.

The Guide also makes a contribution to developing countries and Colombia in particular, since it can use existing equipment in rural and remote areas and provide a solution to the integration of dental diagnostic images for the Ministry of Health and Social Protection as it perpetrates future designs of rules governing the EHR.

\section{Disclosure Statement}

No competing financial interests exist.

${ }^{\mathrm{i}}$ Call for an Integrated (Medical/Dental) Health Care Model that Optimally Supports Chronic Care, Pediatric Care, and Prenatal Care as a Basis for 21st Century EHR Standards and Products: EHR Position Paper.

\section{REFERENCES}

1. Congreso de la República de Colombia. Ley 100 de 1993. Por medio de la cual se crea el Sistema General de Seguridad Social Integral. Libro II. Sistema General de Seguridad Social en Salud. Bogotá, December 1993.

2. Portilla F, Villegas, N, Tamura G. Aspectos claves en la definición y adopción de estándares de interoperabilidad electrónica de datos: El caso de HL7 en el área de la salud. Sist Telemática. 2009;7(14):71-89. Available from: http:/l biblioteca.versila.com/ (last accessed June 13, 2015).

3. Montenegro F, Bernal O. Colombia Case Study: The Subsidized Regime of Colombia's National Health Insurance System. The World Bank. January 2013. Available at http://documents.worldbank.org/curated/en/2013/01/17207398/ colombia-case-study-subsidized-regime-colombias-national-health-insurancesystem (last accessed April 28, 2013).

4. Chernichovsky D, Guerrero R, Martínez G. La Sinfonía inconclusa: La reforma del Sistema de Salud de Colombia. Working Paper. May 2012. Available at www.proesa.org.co/proesa/documentos_de_trabajo.php (last accessed February 2013)

5. Ministerio de Salud Pública y Protección Social. Resolución 5592 del 24 de diciembre de 2015. Por la cual se actualiza integralmente el Plan de Beneficios en Salud con cargo a la Unidad de Pago por Capitación-UPC del Sistema General de Seguridad Social en Salud-SGSSS y se dictan otras disposiciones, p. 220.

6. Heasman P, McCracken G. Harty's dental dictionary. USA: Elsevier Health Sciences, 2007:521.

7. Portilla, F. 2007. Convergencia Tecnológica. 20 Congreso Iberoamericano de Informática Médica Normalizada, Bogotá D.C., s.n., 2007.

8. National Library of Medicine. Dental Informatics. 2010. www.dentalinformatics .com [Online]. (last accessed July 15, 2013).

9. Organización Panamericana de la Salud. Organización Mundial de la Salud. Clasificación Estadistica Internacional de Enfermedades y Problemas Relacionados con la Salud. Décima Revisión. CIE 10 [Online]. Edición 2008. Washington, D.C.: OPS, 1995 Available at www.who.int/classifications/icd/ icd10updates/en/index.html. (last accessed February 6, 2013).

10. De la Cruz E, Lopez DM. Guía_de_implementación_Odontologia.pdf [Online]. 2011:43. Available at http://esalud.unicauca.edu.co/wiki/images/1/17/ Gu\%C3\%ADa_de_implementaci\%C3\%B3n_Odontologia.pdf. (last accessed July 15,2013$)$

11. Universidad Nacional de Colombia. Plan global desarrollo 2010-2012. Final Nov 4 10.pdf [Online]. Available at www.onp.unal.edu.co/docs_curso/descargas/ Planes\%20de\%20Desarrollo/libro\%20Plan\%20global\%20desarrollo\%2020102012\%20final\%20nov\%204\%2010.pdf. (last accessed July 16, 2013).

12. Kamburoğlu K, Kolsuz E, Murat $S$, Yüksel S, Özen T. Proximal caries detection accuracy using intraoral bitewing radiography, extraoral bitewing radiography and panoramic radiography. Dentomaxillofac Radiol 2012;41: 450-459 [Internet].

13. Horner K, Shearer AC, Walker A, Wilson NH. Radiovisiography: An initial evaluation. Br Dent J 1990;168:244-248 [Internet].

14. Portilla F. HL7 y estándares de interoperabilidad en Salud: Nociones básicas y fundamento. $2^{\circ}$ Seminario Regional sobre Salud-e y Telemedicina en América Latina y el Caribe: Prácticas de innovación y estándares. 26-27 de julio de 2011. Caracas, Venezuela.

15. White SC. Radiologia oral. Madrid, Spain: Elsevier España, 2001.

16. Brooks SL, Miles DA. Advances in diagnostic imaging in dentistry. Dent Clin North Am 1993;37:91-111.

17. Lopez, D. Documentos Clínicos Electrónicos. CDA. Interoperabilidad Nivel 1,2 y 3. Estudios de Caso: Colombia y Proyecto Wawared-Perú. [Internet]. HL7 Colombia; 2015. Available from: http://www.minsa.gob.pe/renhice/documentos/ Pre2Jor/02\%20Diego\%20L\%C3\%B3pez\%20-\%20Documentos\%20Cl\%C3\% ADnicos\%20Electr\%C3\%B3nicos\%20CDA.pdf

18. Huang EW, Tseng TL, Chang ML, Pan ML, Liou DM. Generating Standardized Clinical Documents for Medical Information Exchanges. IT Prof 2010; 12:26-32. 


\section{GONZALEZ ET AL.}

19. HL7 Standards Product Brief. CDA® Release 2 ( $r 2$ ). [Internet]. Available from: http://www.hl7.org/implement/standards/product_brief.cfm?product_id=7 (last accessed May 1, 2016).

20. Kaminker D. CDA R2 Alcances, Aplicaciones, Situación actual y Futura. 2do Meeting Group Fundación HL7 Colombia. Marzo, 2008.

21. Chang YJ, Lai JS, Cheng PH, Lai F. Portable CDA for the exchange of clinical documents. 2007 9th International Conference on E-Health Networking Applications and Services. Taiwan: IEEE, 2007;1-5.

22. Indrajit I. Digital imaging and communications in medicine: A basic review. Indian J Radiol Imaging 2007;17:5.

23. Ruiz C, Trujillo A, García A. Aproximación a la representación en xml de objetos dicom para fotografia médica digital. Rev Eia 2007;8:147-163.

24. Patanachai N, Uyyanonvara B, Sinthanayothin $C$, Tharanon $W$, Sompot $P$, Muandet K. PACS (picture archiving communication system) for dentistry. 5th International Conference on Electrical Engineering/Electronics, Computer, Telecommunications and Information Technology, 2008 ECTI-CON. IEEE, $2008 ; 77-80$
25. Larman G. Uml y patrones 2/E [Online]. Available at www.casadellibro.com/ libro-uml-y-patrones-2e/8420534382/872802 (last accessed July 16, 2013).

Address correspondence to:

Marta C. Jaramillo-Mejia, MD, MPH Organizational Management Department

ICESI University

Calle 18 No. 122-135

Cali 76001

Colombia

E-mail: mcjara@icesi.edu.co

Received: December 3, 2015

Accepted: April 5, 2016 